\title{
Otros factores que favorecen la desnutrición en los pacientes de diálisis peritoneal
}

\author{
Elisabet Tejeda Araez, Eva Barbero Narbona, Ernestina Junyent Iglesias, Nuria Pujolar Fulquet
}

\author{
Hospital del Mar de Barcelona
}

\section{Introducción:}

Los pacientes con insuficiencia renal crónica en tratamiento en diálisis peritoneal tienen un riesgo elevado de hipoalbuminemia debido a múltiples causas como la inflamación crónica y las pérdidas a través de la diálisis. El estudio realizado por A. Guerrero et al. ${ }^{1}$ muestra que la pérdida diaria de albúmina en diálisis peritoneal automática fue de media $4 ' 2 \pm 2 \mathrm{gr} / 24 \mathrm{~h}$ similar a los pacientes en diálisis peritoneal continua ambulatoria 4 ' $1 \pm$ $l^{\prime} 2 \mathrm{gr} / 24 \mathrm{~h}$. Existen otros estudios 2,3 que han comunicado pérdidas de albúmina en diálisis peritoneal continua ambulatoria similares a las anteriores. También se ha relacionado ${ }^{4}$ la hipoalbuminemia con peritonitis, debido a un descenso en diversas proteínas, muchas de las cuales pueden ser necesarias para el adecuado funcionamiento del sistema inmunitario. Debido a las consecuencias que puede comportar una disminución del nivel de albúmina sérica en nuestros pacientes decidimos estudiar la relación que existe entre la alteración de niveles de albúmina con diferentes sucesos no vinculados a la terapia.

\section{Objetivo:}

El objetivo es identificar aquellos problemas no relacionados con la terapia de diálisis peritoneal que producen una disminución de albúmina en nuestros pacientes y realizar intervenciones de enfermería.

\section{Material y metodologia:}

Hemos realizado un estudio observacional y retrospectivo desde 2006 a 2012, de todos los pacientes en trata- miento en diálisis peritoneal. Se han estudiado un total de 39 pacientes con un seguimiento bimensual del nivel de albúmina. Se han revisado, analizado y exportado los datos del programa informático PD Adequest*2.0 Baxter, historias clínicas y parámetros analíticos. El procedimiento ha consistido en relacionar los descensos de la albúmina con eventos no vinculados a la terapia mediante revisión exhaustiva de la historia clínica.

\section{Resultados:}

De los 39 pacientes se excluye a uno de ellos por haber estado ingresado durante un mes en la UCI. De los restantes: 10 pacientes mostraron 3 determinaciones de albúmina $<3.5 \mathrm{mg} / \mathrm{dl}$ y 6 pacientes presentan entre 4 y 5 determinaciones de albúmina $<3.5 \mathrm{mg} / \mathrm{dl}$. En un $26.31 \%$ de los pacientes, la disminución del nivel de albúmina está relacionada con un periodo de hospitalización.

\section{Conclusiones:}

A partir de los resultados de este estudio, se decidió suplementar la dieta con proteínas a todos los pacientes de diálisis peritoneal que ingresan en nuestro servicio. En los pacientes en tratamiento de diálisis peritoneal, además de la pérdida de la albúmina que conlleva la propia técnica, existen factores externos que influyen en su estado nutricional, como por ejemplo: determinadas situaciones personales y/o sociales. Hemos añadido herramientas para identificar disfunciones en alguna dimensión de su vida a nivel holístico, como: el cuestionario SF-12, escala de Lawton y Brody, que actúan como 
predictor y nos permiten realizar intervenciones tempranas.

\section{Referencias Bibliográficas}

1. Guerrero A, Montes R, Martín C, MartínezBenavides E, Remón C, Ruiz A, del Pino MD, Fernández-Girón F, Tejuca F, Torán D. Pérdida de albúmina en la diálisis peritoneal automática. Comparación con la diálisis peritoneal ambulatoria continua. Nefrología 1997; XVII (6): 480-485.
2. Blumentkrantz MJ, Ghal GM, Kopple MG, Kamdar AV, Jones MR, Kesselm JK, Coburn JW. Protein losses during peritoneal dialysis. Kidney Int 1981; 19: 593-602.

3. Kagan A, Bar-Khanyim Y, Schafer Z; Fainane M. Kinetics of peritoneal protein loss during CAPD: I. Different characteristics of low and high molecular weight proteins. Kidney Int 1990; 37: 971-979.

4. Huerta S, Rubio AF, Flores G. Hipoalbuminemia severa: factor de riesgo para peritonitis en pacientes en diálisis peritoneal. Med Int Mex 2010; 26(2): 87-94. 